\title{
Modelo de avaliação da sustentabilidade de ciclovias urbanas aplicado à capital brasileira
}

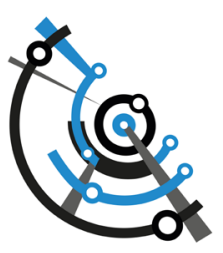

\section{Renata Almeida Motta}

Departamento de Engenharia de Transportes, Universidade de Brasília, Brasil. http://lattes.cnpq.br/5938060455518276

\section{Clarissa Melo Lima}

Departamento de Administração, Universidade de Brasília, Brasil. http://lattes.cnpq.br/6917886925634086

\author{
Augusto César de Mendonça \\ Departamento de Engenharia de Transportes, Universidade de Brasília, Brasil. \\ http://lattes.cnpq.br/0571960641751286
}

\author{
Paulo Cesar Marques da Silva \\ Departamento de Engenharia de Transportes, Universidade de Brasília, Brasil. \\ http://lattes.cnpq.br/1518119916915399
}

Recibido: 26 de septiembre de 2019. Aceptado: 4 de noviembre de 2019.

\begin{abstract}
Resumo
Este artigo propôs um modelo quantitativo usando Dimensões, Características e Indicadores de Sustentabilidade para avaliar a sustentabilidade das ciclovias. O modelo foi aplicado como um estudo de caso a duas ciclovias reais na capital brasileira, Brasília. O processo de seleção de indicadores de sustentabilidade empregou o método Delphi com 9 especialistas seniores da área de transporte e, originalmente, foram identificados 650 indicadores. Estes foram convertidos para fornecer 28 indicadores consolidados. Utilizou-se o método Função Multiatributo Aditiva (Multiattribute Utility Theory) para estabelecer uma hierarquia de dimensões, características e indicadores. Outros nove especialistas definiram níveis de importância e atribuíram pesos a Dimensões, Características e Indicadores. No total, 40 pesos foram atribuídos aos três níveis hierárquicos e o peso final de cada nível foi considerado a média aritmética dos pesos indicados pelos 9 especialistas. Os pesos dos indicadores foram multiplicados pelos pesos de suas respectivas Características e Dimensões, resultando em uma equação para o Índice de Sustentabilidade na forma de uma combinação linear dos pesos com os indicadores. Os usuários das ciclovias analisadas foram entrevistados e atribuíram pontuações a cada
\end{abstract}


um dos indicadores. A partir dessas pontuações, foi possível calcular o indicador de sustentabilidade de cada ciclovia. A ciclovia 2 obteve uma melhor avaliação em relação a ciclovia 1 em todos os cenários de ponderação analisados.

Palavras-chave: Desenvolvimento sustentável. Transporte. Método de Função Multiatributo Aditiva.

\title{
A model for evaluating sustainability applied to two urban cycleways in brasilia
}

\begin{abstract}
This paper proposed a quantitative model using Sustainability Dimensions, Characteristics and Indicators for evaluating the sustainability of cycleways. The model was applied as a case study to two actual cycleways in the Brazilian capital, Brasília. The sustainability indicator selection process employed the Delphi method with 9 senior experts from the field of transportation and originally 650 indicators were identified. These were converted to provide 28 consolidated indicators. Multi-attribute Utility Theory method was used to establish a hierarchy of the Dimensions, Characteristics and Indicators. Nine other experts defined levels of importance and attributed weights to Dimensions, Characteristics and Indicators. 40 weights altogether were attributed to the three hierarchic levels and the final weight for each level was taken to be the arithmetical average of the weights indicated by the 9 experts. The weights of the indicators were multiplied by the weights of their respective Characteristics and Dimensions, resulting in an equation for the Sustainability Index in the form of a linear combination of the weights with the indicators. The users of the analyzed cycleways were interviewed and assigned scores to each of the indicators. From these scores, it was possible to calculate the sustainability indicator of each bicycle path. The cicloway 2 had a better rating compared to cicloway 1 in all weighting scenarios analyzed.
\end{abstract}

Keywords: Sustainable development. Transport. Multi-attribute Utilit Theory method. Palabras clave: Desarrollo sostenible. Transporte. Método de función multiatributo aditivo.

\section{Introdução}

As principais cidades do mundo, particularmente as de maior porte, têm enfrentado desafios nos transportes para lidar com os congestionamentos, acidentes, consumo energético e emissões atmosféricas devido à crescente urbanização e motorização. É de fundamental importância a adoção de instrumentos que auxiliem no controle dos efeitos negativos causados pelo setor de transportes ao meio ambiente, à saúde e ao bem-estar social de suas populações.

Na última década intensificou-se a publicação de artigos, documentos e livros sobre temas como sustentabilidade e desenvolvimento sustentável. No entanto, a explicitação de problemas do setor de transportes, de seu planejamento e de políticas relacionadas à sustentabilidade é ainda recente. O setor de transportes possui grande potencial de aplicação do conceito de sustentabilidade, uma vez que é um dos que mais contribuem nos dias de hoje para o consumo de recursos energéticos e para a emissão de poluentes locais e Gases de Efeito Estufa - GEE (International Energy Agency, 2017).

A avaliação quantitativa da sustentabilidade pode ser uma boa ferramenta no processo de tomada de decisões que contemplem as demandas da sociedade em harmonia ao meio ambiente. A Comissão de Desenvolvimento Sustentável (Comission on Sustanaible 
Development - CSD), criada pela Organização das Nações Unidas (ONU), considera ser de fundamental importância a criação de padrões que sirvam de referência para medir o progresso da sociedade em direção a um futuro sustentável por meio de uma base mundial, uma vez que a maioria dos indicadores existentes não é adequada para se alcançar esse objetivo.

Os desafios da sociedade para maior sustentabilidade, têm incentivado a revisão dos conceitos, formas de planejamento e gestão urbana, principalmente no que diz respeito às questões relacionadas ao setor de transportes e mobilidade. Muitos pesquisadores e agentes públicos têm buscado novas formas de analisar, discutir e encontrar soluções para as questões da mobilidade sustentável, com adoção de estratégias que reduzam a demanda de viagens por transporte individual e que incentivem o uso de sistemas mais sustentáveis adequados ao contexto socioeconômico de cada região. Como exemplo, podemos citar os trabalhos da década de 90, de Massen, Svidén, e Wegener (1992), e mais posteriormente Litman (1999) que aponta a necessidade de uma mudança (shift) na direção da mobilidade sustentável por parte dos planejadores. Essa visão resultou mais recentemente na abordagem Avoid-Shift-Improve (ASI) proposta por Dalkmann e Brannigan (2007). Neste sentido, o transporte por bicicleta tem sido uma opção de várias cidades, em diversos países, para a maior sustentabilidade da mobilidade urbana (Batabyal \& Nijkamp, 2013; Yai \& Suzuki, 2011). No entanto, a decisão sobre a implantação de ciclovias urbanas requer uma avaliação do grau de sustentabilidade dessa ação, contemplando os aspectos das dimensões Econômica, Social e Ambiental. Para isso, são necessárias ferramentas e modelos que permitam uma avaliação quantitativa, que consiga captar a influência das três dimensões. Adicionalmente, um modelo quantitativo do grau de sustentabilidade de ciclovias requer o uso de indicadores de sustentabilidade para cada dimensão.

A exemplo do que ocorreu em várias cidades mundiais, a capital do Brasil teve grandes investimentos na malha ciclo viária nos últimos anos, aumentando de $160 \mathrm{~km}$ em 2011, para $465 \mathrm{~km}$ em 2018 (Velasco et al., 2018). E semelhantemente às cidades brasileiras que tiveram um grande crescimento da malha ciclo viária na última década, a implantação das ciclovias em Brasília não passou por uma avaliação de sustentabilidade do investimento. Para preencher essa lacuna, o presente trabalho propõe um modelo de avaliação quantitativa de sustentabilidade de ciclovias, com o uso de indicadores de mobilidade sustentável de ciclovias, que poderá auxiliar em diretrizes para implantação de ciclovias mais sustentáveis.

\section{Sustentabilidade e mobilidade sustentável}

Repetto and Magrath (1988) estabelecem inicialmente em seu trabalho, que a sustentabilidade deve ter como base, as decisões atuais que não acarretem nenhum prejuízo ao padrão de vida no futuro. Os autores evoluem o tema sobre desenvolvimento econômico e sustentabilidade, e argumentam que, naquele ano, não havia contabilização quanto à conservação, ou não, dos recursos naturais e nem quanto aos aspectos socioeconômicos da sustentabilidade. Havia naquela época, portanto, uma grande assimetria na forma de pensar e medir o valor dos recursos naturais e contemplá-los como ativos econômicos. O trabalho mostra uma boa abordagem sobre a depreciação do capital dos recursos naturais, e apresenta uma correlação da variação do PIB com a depreciação de recursos naturais, especialmente em países em desenvolvimento com uso intenso de seus recursos naturais.

A Comissão Mundial Sobre o Meio Ambiente (1987) em seu relatório Nosso Futuro Comum propõe que no desenvolvimento sustentável a exploração dos recursos ambientais deve ser feita de maneira a permitir o tempo necessário para que a natureza se 
recupere e, consequentemente mantenha o equilíbrio ambiental. Essa definição se restringe à quantidade de recursos naturais e o tempo (para renovação dos recursos naturais) como variáveis da sustentabilidade. Consequentemente, para efeito dessa definição, a sustentabilidade é uma função apenas da quantidade q de recursos naturais ao longo do tempo t. Se definirmos $\mathrm{S}$ como sendo a sustentabilidade de um recurso natural cuja quantidade é q, então:

$$
S=S(q) \quad(\text { Eq. } 1)
$$

Se, ainda, a quantidade de recurso natural q varia com o tempo:

$$
q=q(t) \quad \text { (Eq. 2) }
$$

Para os vários recursos naturais existentes, e explorados, a sustentabilidade não é função apenas da quantidade de um recurso natural, mas da quantidade de um conjunto de recursos naturais (Fernandez, 2014). Sendo assim:

$$
q=\left\{\begin{array}{c}
q_{1}(t) \\
q_{2}(t) \\
q_{3}(t) \\
\cdot \\
\cdot \\
q_{n}(t)
\end{array}\right.
$$

(Eq. 3)

$$
S(t)=a_{1} q_{1}(t)+a_{2} q_{2}(t)+a_{3} q_{3}(t)+\cdots+a_{n} q_{n}(t)
$$

Onde $a_{n}$ representa um coeficiente de peso de $q_{n}$.

No seguimento dessa mesma ideia, Pearce e Atkinson (1993) estabelecem que para a existência de desenvolvimento sustentável, é necessário que existam condições de manter um estoque de Capital sempre constante. Os autores definem Capital como a composição do Capital Humano e do Capital Natural, sendo possível assumir aqui que pode haver substituição de um pelo outro mantendo a sustentabilidade.

Portanto, para Pearce e Atkinson (1993), Repetto e Magrath (1988) e Turner (1993) a sustentabilidade é uma função do estoque de Capital Humano, Kh, e de Capital Natural, Kn:

$$
S=S\left(K_{h}+K_{n}\right)
$$

(Eq. 5)

Contudo, a hipótese de capital carece ainda de uma consideração sobre a existência de depreciação ou aumento de capital. E consequentemente, só pode haver sustentabilidade se $\mathrm{o}$ aumento do capital total for maior que a depreciação.

Nessa linha de definição sobre a depreciação e o aumento (ou estoque) de capital, Pezzey (1992) propôs conceitos de crescimento sustentável, desenvolvimento sustentável e uso sustentável dos recursos. Para o autor, os critérios de sustentabilidade devem ser originados de uma base ética de equidades e, portanto, a escolha de critérios de 
sustentabilidade requer a adequação aos contextos políticos e socioeconômicos, onde os recursos, naturais ou não, são "entradas" (inputs) para a produção e riqueza. Pezzey (1992) ainda estabelece que tais critérios devem levar em conta o quanto os recursos são essenciais e substituíveis, o que num sistema produtivo significa considerar o maquinário utilizado, o conhecimento técnico e o tipo de matéria prima (renovável ou não-renovável).

Ainda sobre desenvolvimento histórico do conceito de sustentabilidade para aplicação no presente trabalho, Faber et al. (2005) fizeram uma boa revisão sobre os diversos conceitos de sustentabilidade com o objetivo de encontrar um ou dois que pudessem ser amplamente aplicados, entretanto, conseguiram destacar 50 conceitos. De acordo com os autores, a sustentabilidade em sua essência não pode ser determinada de forma simplista uma vez que o conceito pode sofrer influências culturais e organizacionais resultantes de debates sobre o assunto.

Portanto, para convergir a uma definição de sustentabilidade, Faber et al. (2005) estabeleceram três propriedades. A propriedade considerada mais importante foi denominada de "ativo" (the artefact) que define "o que" deve ser sustentável. A outra propriedade é a "orientação do objetivo" (goal orientation), a qual trata o quanto é sustentável o ativo, definindo se a sustentabilidade é absoluta ou relativa. Na orientação absoluta a sustentabilidade pode ocupar dois extremos: sustentável ou não sustentável. A orientação relativa é mais próxima da realidade, uma vez que os problemas de sustentabilidade são mais ou menos sustentáveis, e variam historicamente tendendo para uma solução qualquer. Os autores afirmam que a distinção entre a sustentabilidade absoluta e a relativa lembra a distinção entre uma ação utópica e uma ação prática, respectivamente. A terceira propriedade trata da interação comportamental (interaction), estática ou dinâmica, que foi originada da hipótese de que os ativos e seus ambientes sofrem mudanças em seus componentes e relações. Na interação estática o ativo é dinâmico e o ambiente é estático, ou seja, ocorrendo uma mudança do ativo, a sustentabilidade só é garantida pela limitação do ambiente. Na interação dinâmica há mudanças tanto no ativo como no ambiente e, consequentemente, influencia o equilíbrio da sustentabilidade. Para alcançar a sustentabilidade, o ativo acompanha as mudanças no ambiente adaptando-se continuamente para manter o equilíbrio. De acordo com Faber et al. (2005) a sustentabilidade explica a relação entre o ativo e seu meio, e estabelece o quanto essa relação é sustentável.

Partindo dos conceitos mais ampliados vistos acima, a sustentabilidade deixa de ser uma função somente das quantidades de recursos naturais e passa a ser uma função dos ativos. Ao longo deste trabalho, sob o ponto de vista da mobilidade e das relações entre sociedade e ambiente, os ativos (At) receberão as dimensões Ambiental, Econômico e Social. Assim, cada ativo é uma função de variáveis independentes de sustentabilidades, $\mathrm{S}(\mathrm{I}(\mathrm{t})$ ), onde a orientação (goal of orientation) representa um indicador de sustentabilidade (I) relativo à variável $\mathrm{S}$.

$$
A t=\left\{\begin{array}{c}
S_{1}\left(I_{1}\right) \\
S_{2}\left(I_{2}\right) \\
S_{3}\left(I_{3}\right) \\
\cdot \\
\cdot \\
\cdot \\
S_{i}\left(I_{i}\right)
\end{array}\right.
$$


Sendo assim, se existe uma sustentabilidade global S, ela pode ser considerada uma função da combinação linear das sustentabilidades independentes:

$$
S(t)=a_{1} S_{1}\left(I_{1}(t)\right)+a_{2} S_{2}\left(I_{2}(t)\right)+a_{3} S_{3}\left(I_{3}(t)\right)+\cdots+a_{n} S_{n}\left(I_{n}(t)\right)
$$

\section{Definição das Dimensões e Indicadores de Sustentabilidade}

Como visto acima, os ativos podem receber dimensões que são quantificadas por indicadores (goal of orientation) e, portanto, para efeito deste trabalho, a partir daqui serão usados os termos Dimensões e Indicadores.

O presente trabalho aproveita as dimensões que já foram tradicionalmente usadas em estudos de sustentabilidade nos últimos anos, bem como, indicadores de sustentabilidade vinculados às respectivas dimensões.

A maioria dos trabalhos disponíveis na literatura, sobre avaliação de sustentabilidade, incluindo mobilidade sustentável, utilizam indicadores nas três dimensões tradicionais: Ambiental, Social e Econômica. Alguns autores utilizaram indicadores com mais dimensões além das três tradicionais (Litman, 2008). Renne (2008), por exemplo, utilizou seis dimensões para avaliar a sustentabilidade nos transportes, incluindo o Padrão de Viagens, o Ambiente Construído e o Contexto de Políticas Públicas.

No caso específico da definição e avaliação de mobilidade sustentável, Mitropoulos and Prevedouros (2016) realizaram uma revisão objetiva sobre o assunto, e desenvolveram uma avaliação de sustentabilidade no planejamento dos transportes, com base em indicadores dentro de cinco dimensões: Ambiental, Tecnologia, Energia, Economia e Usuários dos transportes. Tal avaliação incluiu o uso de veículo de transportes coletivos e individuais. No trabalho de Jain and Tiwari (2017)and that are measurable and achievable at the same time. Indicator selection frameworks - criteria based; causal chains and causal networks have been proposed and used in the past. All three frameworks have certain limitations and strengths. In this study we have proposed a systematic approach of selecting sustainable mobility indicators for Indian cities by combining criteria based, causal chain and causal network frameworks. The methodology involves both subjective judgments for evaluation of indicators against a set of criteria and objectivity during development and assessment of causal network. The method results in identifying 20 relevant factors for which 32 indicators are shortlisted. Further work is required to develop measurable indicators related to accessibility to the disadvantaged, speed limit restriction and street lighting. These have not been discussed in detail in the existing literature. The 20 factors are classified as root nodes, central and end-ofthe-chain nodes that helps in identifying levers of attaining sustainable mobility in Indian cities. The developed causal network is evaluated for its ability to address all sectors associated with sustainable mobility. The causal network has low density and centralization index and therefore accounts for multiple factors. The shortlisted indicators are proposed for preparing low carbon mobility plan (LCMP, foi feita uma boa revisão sobre sustentabilidade e apresentados quais critérios são adequados na seleção dos indicadores a serem usados em um modelo de avaliação de mobilidade sustentável. Os autores propuseram um método de seleção de indicadores de mobilidade sustentável para cidades da Índia, com base nas três dimensões tradicionais de sustentabilidade: Social, Ambiental e Econômica.

Para efeito do presente trabalho, os indicadores Ii são definidos como os indicadores de sustentabilidade de ciclovias urbanas, atribuídos em três dimensões de sustentabilidade: Ambiental, Econômico e Social. O modelo deste trabalho propõe uma Sustentabilidade 
Global, ou um Índice de Sustentabilidade, de ciclovias com base em indicadores de sustentabilidade nas três dimensões.

Aplicando a Eq. 7 descrita acima, define-se aqui um Índice de Sustentabilidade (S) de ciclovias, com base nas dimensões Ambiental (Env), Econômico (Econ) e Social (Soc):

$$
S I=a_{1} \times(E n v)+a_{2} \times(E c o n)+a_{3} \times(S o c)
$$

Onde, para cada dimensão, foram atribuídos os respectivos indicadores de sustentabilidade Ienv, Iecon e Isoc:

$$
\begin{aligned}
& E n v=b_{1} \text { Ienv }_{1}+b_{2} \text { Ienv }_{2}+b_{3} \text { Ienv }_{3}+\cdots+b_{n} \text { Ienv }_{n} \\
& \text { Econ }=c_{1} \text { Iecon }_{1}+c_{2} \text { Iecon }_{2}+c_{3} \text { Iecon }_{3}+\cdots+c_{n} \text { Iecon }_{n} \\
& \text { Soc }=d_{1} \text { Isoc }_{1}+d_{2} \text { Isoc }_{2}+d_{3} \text { IsOC }_{3}+\cdots+d_{n} \text { IsOC }_{n}
\end{aligned}
$$

\section{Determinação de indicadores de sustentabilidade de ciclovias}

Para Afgan et al. (2000) os indicadores de sustentabilidade devem ser medidos com ferramentas confiáveis que devem ser um pré-requisito para a determinação de processos sustentáveis. Para a avaliação de um sistema de energia utilizando indicadores de sustentabilidade Afgan et al. (2000) utilizaram a literatura disponível com dados relacionados à produção total de energia, tendo por base quatro grupos de indicadores cujos critérios foram os recursos energéticos, o ambiente, o econômico e o social. Segundo Parris and Kates (2003)but some combination of development and environment as well as equity is found in many attempts to describe it. However, proponents of sustainable development differ in their emphases on what is to be sustained, what is to be developed, how to link environment and development, and for how long a time. Despite the persistent definitional ambiguities associated with sustainable development, much work (over 500 efforts, os indicadores de sustentabilidade são construídos a partir de dados disponíveis cujas origens são diversificadas. Além disso, alguns dados são extrapolados o que contribui para uma alta variação entre os indicadores.

Afgan et al. (2000) realizaram uma modelagem para sistemas de energia considerando um índice de sustentabilidade. Os critérios utilizados foram os mesmos utilizados em Afgan et al. (2000), ou seja, indicadores de recursos energéticos, sociais, ambientais e econômicos.

De acordo com Bellen (2002) os métodos mais usados para avaliação de sustentabilidade propõem boas listas de indicadores qualitativos, mas não desenvolvem um modelo quantitativo e que considere os valores dos indicadores. Já Litman (2008), afirma sobre a necessidade da utilização de um conjunto de indicadores para avaliar a sustentabilidade, mas ao mesmo tempo ressalta a inviabilidade de aplicar todos os indicadores existentes, devido às limitações de disponibilidade de dados, custos de coleta e análise. Portanto, para a devida avaliação de sustentabilidade, é fundamental priorizar os indicadores mais importantes para o modelo de sustentabilidade. 
No Brasil, a melhor referência sobre a avaliação da mobilidade com uso de indicadores de sustentabilidade, é o trabalho de Costa (2008) que desenvolveu o Índice de Mobilidade Sustentável (IMUS), com base nas três dimensões tradicionais. O IMUS foi aplicado em outros trabalhos após Costa (2008), tais como Silva et al. (2010), Pontes (2010) e Costa et al. (2017).

O presente trabalho tomou como referência a literatura citada acima para desenvolvimento do modelo de avaliação de sustentabilidade de ciclovias, com base em indicadores. Contudo, foi necessário estabelecer a metodologia e os critérios de definição de quais indicadores seriam usados no modelo, bem como, foi necessário também estabelecer a metodologia para atribuição de importância de cada indicador dentro de cada dimensão.

\section{Metodologia para a definição dos Indicadores de Sustentabilidade de Ciclovias}

A Figura 1 apresenta na forma de fluxograma a metodologia utilizada para a construção dos indicadores de análise de ciclovias.

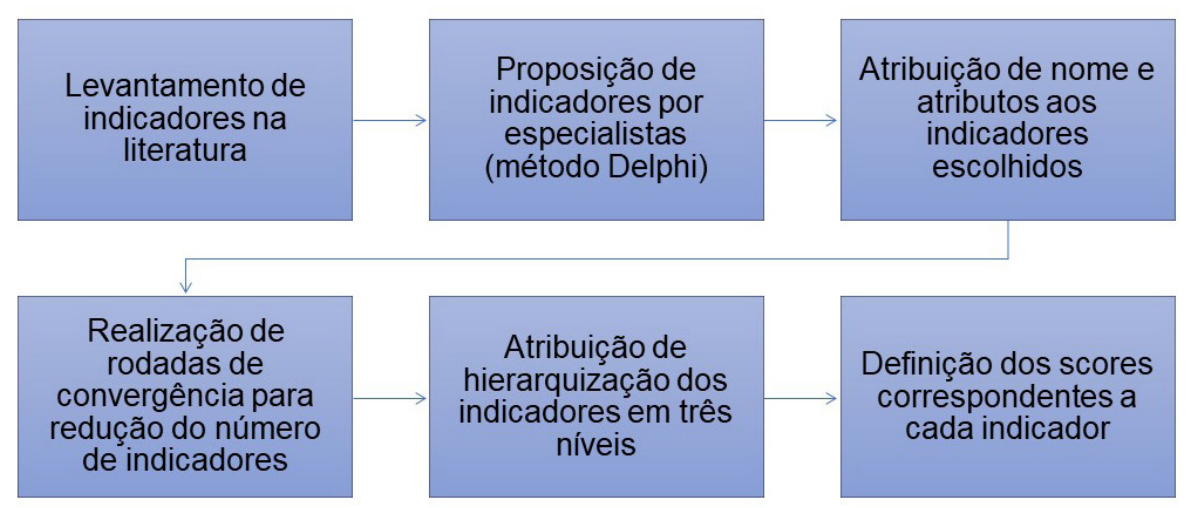

Figura 1. Fluxograma ilustrativo da metodologia do trabalho. Fonte: Autores.

Na sequência, cada passo do fluxograma da Figura 1 é detalhado.

Inicialmente, foram levantados 650 indicadores da revisão da literatura, como uma base para a construção dos indicadores aplicáveis ao modelo. Oito especialistas sêniores da área de transportes foram escolhidos para avaliar, incluir, modificar e propor indicadores. O processo de convergência dos indicadores de sustentabilidade foi realizado pelo método de Delphi (Álvarez \& Torrado-Fonseca, 2016). A cada indicador foi atribuído um nome, dimensão de sustentabilidade, descrição, unidade de medida, como medir e um valor normalizado, a ser descrito no próximo item.

Duas rodadas de convergência foram feitas reduzindo incialmente para 39 indicadores, e posteriormente reduzindo para 28 indicadores de mobilidade sustentável aplicáveis em ciclovias. Os critérios de escolha de indicadores sugeridos aos especialistas, levaram em conta os seguintes:

» O conceito Triple Bottom Line, proposto por Elkington (1994), utilizando as dimensões social, econômica e ambiental;

» Recomendações do guia de auxílio à seleção de indicadores de mobilidade sustentável de Litman (2008), com a seleção de indicadores de fácil coleta, resultando em 
dados obtidos diretamente em instituições ligadas à mobilidade urbana, e informações obtidas com pesquisas de opinião aos ciclistas.

\section{Hierarquização}

Para estabelecer a hierarquia das dimensões e dos indicadores, foi aplicado o método de Função Multiatributo Aditiva (Multiattribute Utility Theory) (Costa, 2008). Em uma primeira etapa da metodologia Função Multiatributo Aditiva, com base na avaliação dos especialistas, foram definidos três níveis, hierárquicos. No primeiro nível hierárquico, têm-se as dimensões de sustentabilidade: ambiental, econômica e social. No segundo nível, têm-se as características desejáveis. No terceiro nível têm-se os indicadores de sustentabilidade (Figura 2). No Quadro 1 estão detalhadas as dimensões, características e indicadores.

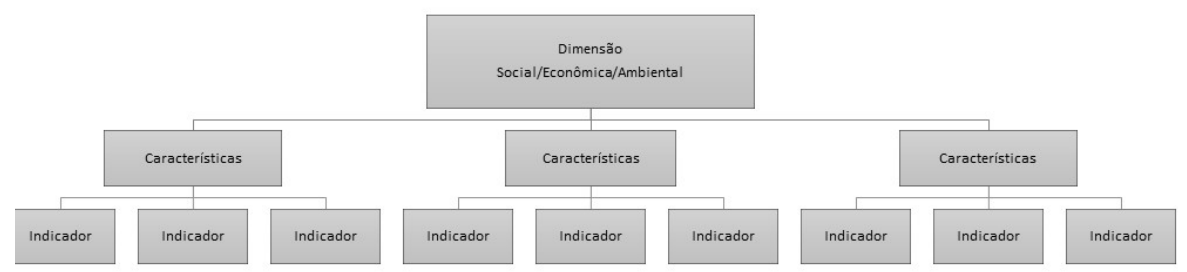

Figura 2. Estrutura dos níveis de hierarquização das Dimensões, Características e Indicadores de Sustentabilidade. Fonte: Autores.

\section{Metodologia para atribuição da importância dos indicadores (Scores)}

Para a segunda etapa da metodologia Função Multiatributo Aditiva, foram selecionados nove especialistas; sendo três representantes do meio acadêmico, três profissionais da área de mobilidade e três representantes da sociedade civil. A escolha dos especialistas buscou equilibrar a visão acadêmica e teórica, a visão institucional pública do gestor e planejador urbano, e o usuário; todos com experiência em atuação na área do uso da bicicleta na mobilidade urbana. Como representantes do meio acadêmico foram selecionados três professores da Pós-Graduação de Transportes da Universidade de Brasília, com doutorado na área, sendo um deles Diretor do Centro Interdisciplinar de Estudos em Transportes da Universidade de Brasília (CEFTRU). Como representantes da área institucional pública de gestão e planejamento, foram selecionados três mestres em Engenharia de Transportes: um Diretor da Secretaria Nacional de Transportes e da Mobilidade Urbana do Ministério das Cidades, um representante da Secretaria de Política Nacional de Transportes do Ministério dos Transportes; e um servidor da Companhia de Planejamento do Distrito Federal - CODEPLAN. Como representantes da sociedade civil e usuários de bicicletas, foram selecionados três representantes: $\mathrm{o}$ Presidente da Organização Não Governamental - ONG - Rodas da Paz; o Presidente do Instituto Pedala Brasília de Mobilidade Sustentável; e a Fundadora e Coordenadora da ONG Rebas do Cerrado. Ao todo, cada especialista atribuiu 40 pesos somando-se todas as variáveis do método. A função do peso é dar a devida relevância à variável em questão de acordo com as preferências e experiência dos especialistas. . No total, cada especialista atribuiu 40 pesos para todos os três níveis mostrados na Figura 1. Os pesos atribuídos às Dimensões, Características e Indicadores, tiveram o objetivo de representar a respectiva importância de cada variável, de acordo com a visão, preferências e experiência dos especialistas, e o valor final do peso em cada nível foi representado pela média aritmética dos pesos dos 9 especialistas.

Para o primeiro nível hierárquico, das Dimensões, a soma dos pesos foi definida como 1 (ou 100\%) e cada especialista atribuiu um peso para cada dimensão: Social, Ambiental 
e Econômica desde a soma dos pesos das dimensões fosse 1. Os pesos atribuídos ao nível hierárquico das Dimensões são mostrados no Quadro 1.

Quadro 1. Atribuição dos pesos das Dimensões de Sustentabilidade pelos especialistas. Fonte: Autores.

\begin{tabular}{|l|l|l|l|l|l|l|l|l|l|l|}
\hline Pesos/Especialistas & $\mathbf{1}$ & $\mathbf{2}$ & $\mathbf{3}$ & $\mathbf{4}$ & $\mathbf{5}$ & $\mathbf{6}$ & $\mathbf{7}$ & $\mathbf{8}$ & $\mathbf{9}$ & Média \\
\hline Social & $40 \%$ & $60 \%$ & $40 \%$ & $40 \%$ & $50 \%$ & $30 \%$ & $33,30 \%$ & $40 \%$ & $20 \%$ & $39,30 \%$ \\
\hline Ambiental & $40 \%$ & $25 \%$ & $35 \%$ & $40 \%$ & $30 \%$ & $30 \%$ & $33,30 \%$ & $35 \%$ & $30 \%$ & $33,10 \%$ \\
\hline Econômica & $20 \%$ & $15 \%$ & $25 \%$ & $20 \%$ & $20 \%$ & $40 \%$ & $33,30 \%$ & $25 \%$ & $50 \%$ & $27,60 \%$ \\
\hline
\end{tabular}

Assumindo os valores médios das Dimensões atribuídas, apresentados no Quadro 1, pode-se rescrever a Eq. 8 como:

$$
S I=0,393 \times(S o c)+0,331 \times(E n v)+0,276 \times(\text { Econ })
$$

Para o segundo nível hierárquico, das Características, o procedimento adotado foi semelhante ao nível anterior, e novamente cada especialista atribuiu um peso para cada característica desde a soma dos pesos fosse 1 (ou 100\%). Os pesos atribuídos ao nível hierárquico das Características para as Dimensões Social, Ambiental e Econômica, são mostrados no Quadro 2. Contudo, posteriormente o resultado das médias dos pesos das Características foram ponderados pelos pesos de suas respectivas Dimensões apresentados no Quadro 1, por exemplo, para a Característica de nome "Promoção de acessibilidade e integração com sistemas de transporte público" (Quadro 2) o valor da média do peso de $40 \%$ foi multiplicado pelo peso da Dimensão Social de 39,5\% (Quadro 1), resultando em um peso de 15,72\%. Esse procedimento foi feito para todos os valores dos pesos do nível hierárquico das Características, mostrados no Quadro 8.

Quadro 2. Atribuição dos pesos das Características de Sustentabilidade pelos especialistas para a Dimensão Social. Fonte: Autores.

\begin{tabular}{|l|l|l|l|l|l|l|l|l|l|l|}
\hline Pesos/Especialistas & $\mathbf{1}$ & $\mathbf{2}$ & $\mathbf{3}$ & $\mathbf{4}$ & $\mathbf{5}$ & $\mathbf{6}$ & $\mathbf{7}$ & $\mathbf{8}$ & $\mathbf{9}$ & Média \\
\hline $\begin{array}{l}\text { Promoção de acessibilidade e } \\
\text { integração com sistemas de transporte } \\
\text { público }\end{array}$ & $40 \%$ & $40 \%$ & $30 \%$ & $30 \%$ & $30 \%$ & $60 \%$ & $30 \%$ & $30 \%$ & $70 \%$ & $40,00 \%$ \\
\hline $\begin{array}{l}\text { Promoção de segurança durante a } \\
\text { mobilidade dos ciclistas }\end{array}$ & $40 \%$ & $50 \%$ & $40 \%$ & $40 \%$ & $50 \%$ & $25 \%$ & $60 \%$ & $50 \%$ & $20 \%$ & $41,70 \%$ \\
\hline Promoção de saúde e lazer & $20 \%$ & $10 \%$ & $30 \%$ & $30 \%$ & $20 \%$ & $15 \%$ & $10 \%$ & $20 \%$ & $10 \%$ & $18,30 \%$ \\
\hline
\end{tabular}

Quadro 3. Atribuição dos pesos das Características de Sustentabilidade pelos especialistas para a Dimensão Econômica. Fonte: Autores.

\begin{tabular}{|l|l|l|l|l|l|l|l|l|l|l|}
\hline Pesos/Especialistas & $\mathbf{1}$ & $\mathbf{2}$ & $\mathbf{3}$ & $\mathbf{4}$ & $\mathbf{5}$ & $\mathbf{6}$ & $\mathbf{7}$ & $\mathbf{8}$ & $\mathbf{9}$ & Média \\
\hline Promoção de equidade & $40 \%$ & $65 \%$ & $25 \%$ & $40 \%$ & $35 \%$ & $20 \%$ & $60 \%$ & $10 \%$ & $30 \%$ & $36,10 \%$ \\
\hline $\begin{array}{l}\text { Redução de custos } \\
\text { provenientes de acidentes com } \\
\text { ciclistas na região }\end{array}$ & $30 \%$ & $25 \%$ & $50 \%$ & $30 \%$ & $50 \%$ & $40 \%$ & $20 \%$ & $50 \%$ & $30 \%$ & $36,10 \%$ \\
\hline $\begin{array}{l}\text { Redução de custo de poluição } \\
\text { atmosférica }\end{array}$ & $30 \%$ & $10 \%$ & $25 \%$ & $30 \%$ & $15 \%$ & $40 \%$ & $20 \%$ & $40 \%$ & $40 \%$ & $27,80 \%$ \\
\hline
\end{tabular}


Quadro 4. Atribuição dos pesos das Características de Sustentabilidade pelos especialistas para a

Dimensão Ambiental. Fonte: Autores.

\begin{tabular}{|l|l|l|l|l|l|l|l|l|l|l|}
\hline Pesos/Especialistas & $\mathbf{1}$ & $\mathbf{2}$ & $\mathbf{3}$ & $\mathbf{4}$ & $\mathbf{5}$ & $\mathbf{6}$ & $\mathbf{7}$ & $\mathbf{8}$ & $\mathbf{9}$ & Média \\
\hline $\begin{array}{l}\text { Redução de emissão de poluentes } \\
\text { atmosféricos }\end{array}$ & $70 \%$ & $40 \%$ & $33,33 \%$ & $30 \%$ & $25 \%$ & $30 \%$ & $35 \%$ & $50 \%$ & $40 \%$ & $39,30 \%$ \\
\hline $\begin{array}{l}\text { Redução do nível de pressão } \\
\text { sonora }\end{array}$ & $10 \%$ & $10 \%$ & $33,33 \%$ & $20 \%$ & $25 \%$ & $10 \%$ & $25 \%$ & $20 \%$ & $20 \%$ & $19,30 \%$ \\
\hline $\begin{array}{l}\text { Requalificação urbana e } \\
\text { minimização de danos ao meio } \\
\text { ambiente }\end{array}$ & $20 \%$ & $50 \%$ & $33,33 \%$ & $50 \%$ & $50 \%$ & $60 \%$ & $40 \%$ & $30 \%$ & $40 \%$ & $41,40 \%$ \\
\hline
\end{tabular}

Para o último nível hierárquico, dos Indicadores, o procedimento adotado foi semelhante aos níveis anteriores, e cada especialista atribuiu um peso para cada Indicador desde a soma dos pesos fosse 1 (ou 100\%). Os valores originais atribuídos pelos especialistas estão apresentados no Quadro 5.

Quadro 5. Atribuição dos pesos dos Indicadores de Sustentabilidade pelos especialistas. Fonte: Autores.

\begin{tabular}{|c|c|c|c|c|c|c|c|c|c|c|c|}
\hline Indicador & Variável & 1 & 2 & 3 & 4 & 5 & 6 & 7 & 8 & 9 & Média \\
\hline $\begin{array}{l}\text { Volume de bicicletas na } \\
\text { ciclovia }\end{array}$ & ISoc1 & $40 \%$ & $10 \%$ & $30 \%$ & $10 \%$ & $10 \%$ & $10 \%$ & $15 \%$ & $40 \%$ & $20 \%$ & $20,60 \%$ \\
\hline $\begin{array}{l}\text { Existência de áreas comerciais } \\
\text { e unidades de ensino dentro } \\
\text { de uma distância de } 500 \\
\text { metros da ciclovia }\end{array}$ & ISoc2 & $10 \%$ & $10 \%$ & $20 \%$ & $10 \%$ & $40 \%$ & $25 \%$ & $20 \%$ & $15 \%$ & $15 \%$ & $18,30 \%$ \\
\hline $\begin{array}{l}\text { Percentual de viagens de } \\
\text { ciclistas por motivo de } \\
\text { trabalho ou estudo }\end{array}$ & ISoc3 & $10 \%$ & $30 \%$ & $20 \%$ & $24 \%$ & $30 \%$ & $25 \%$ & $30 \%$ & $15 \%$ & $25 \%$ & $23,20 \%$ \\
\hline $\begin{array}{l}\text { Disponibilidade de } \\
\text { estacionamentos de bicicletas } \\
\text { junto à ciclovia }\end{array}$ & ISoc4 & $20 \%$ & $20 \%$ & $10 \%$ & $26 \%$ & $10 \%$ & $10 \%$ & $15 \%$ & $15 \%$ & $15 \%$ & $15,70 \%$ \\
\hline Integração intermodal & ISocs & $20 \%$ & $30 \%$ & $20 \%$ & $30 \%$ & $10 \%$ & $30 \%$ & $20 \%$ & $15 \%$ & $25 \%$ & $22,20 \%$ \\
\hline $\begin{array}{l}\text { Percepção do ciclista com } \\
\text { relação a furtos e roubos na } \\
\text { ciclovia }\end{array}$ & ISoc6 & $10 \%$ & $10 \%$ & $25 \%$ & $12 \%$ & $5 \%$ & $20 \%$ & $10 \%$ & $10 \%$ & $10 \%$ & $12,40 \%$ \\
\hline $\begin{array}{l}\text { Frequência de policiamento } \\
\text { nas imediações da ciclovia }\end{array}$ & ISoc7 & $10 \%$ & $20 \%$ & $15 \%$ & $12 \%$ & $5 \%$ & $20 \%$ & $10 \%$ & $10 \%$ & $10 \%$ & $12,40 \%$ \\
\hline $\begin{array}{l}\text { Localização espacial e } \\
\text { conectividade com outras } \\
\text { ciclovias }\end{array}$ & ISoc8 & $10 \%$ & $15 \%$ & $10 \%$ & $16 \%$ & $30 \%$ & $10 \%$ & $20 \%$ & $30 \%$ & $10 \%$ & $16,80 \%$ \\
\hline $\begin{array}{l}\text { Qualidade da sinalização da } \\
\text { ciclovia, dos cruzamentos } \\
\text { ciclo viários e do tratamento } \\
\text { dos locais críticos }\end{array}$ & ISoc9 & $30 \%$ & $20 \%$ & $5 \%$ & $20 \%$ & $5 \%$ & $20 \%$ & $25 \%$ & $30 \%$ & $30 \%$ & $20,60 \%$ \\
\hline $\begin{array}{l}\text { Qualidade do pavimento da } \\
\text { ciclovia }\end{array}$ & ISoc10 & $20 \%$ & $10 \%$ & $15 \%$ & $18 \%$ & $5 \%$ & $5 \%$ & $10 \%$ & $5 \%$ & $20 \%$ & $12,00 \%$ \\
\hline $\begin{array}{l}\text { Qualidade da drenagem da } \\
\text { ciclovia }\end{array}$ & ISoc11 & $10 \%$ & $10 \%$ & $5 \%$ & $6 \%$ & $30 \%$ & $5 \%$ & $10 \%$ & $5 \%$ & $5 \%$ & $9,60 \%$ \\
\hline $\begin{array}{l}\text { Disponibilização de } \\
\text { iluminação pública nos } \\
\text { arredores da ciclovia }\end{array}$ & ISoc12 & $10 \%$ & $15 \%$ & $25 \%$ & $16 \%$ & $20 \%$ & $20 \%$ & $15 \%$ & $10 \%$ & $15 \%$ & $16,20 \%$ \\
\hline Promoção de saúde & ISoc13 & $30 \%$ & $15 \%$ & $30 \%$ & $25 \%$ & $30 \%$ & $20 \%$ & $40 \%$ & $25 \%$ & $40 \%$ & $28,30 \%$ \\
\hline $\begin{array}{l}\text { Promoção de atividade de } \\
\text { lazer }\end{array}$ & ISoc14 & $30 \%$ & $25 \%$ & $30 \%$ & $25 \%$ & $30 \%$ & $20 \%$ & $10 \%$ & $25 \%$ & $40 \%$ & $26,10 \%$ \\
\hline
\end{tabular}




\begin{tabular}{|c|c|c|c|c|c|c|c|c|c|c|c|}
\hline $\begin{array}{l}\text { Promoção de qualidade de } \\
\text { vida e redução do nível de } \\
\text { estresse dos ciclistas }\end{array}$ & ISoc15 & $40 \%$ & $60 \%$ & $40 \%$ & $50 \%$ & $40 \%$ & $60 \%$ & $50 \%$ & $50 \%$ & $20 \%$ & $45,60 \%$ \\
\hline $\begin{array}{l}\text { Percentual de ciclistas } \\
\text { que não possuem veículo } \\
\text { particular }\end{array}$ & IEcon1 & $25 \%$ & $10 \%$ & $20 \%$ & $15 \%$ & $30 \%$ & $5 \%$ & $20 \%$ & $10 \%$ & $30 \%$ & $18,30 \%$ \\
\hline $\begin{array}{l}\text { Percentual de transferência do } \\
\text { modo a pé para o ciclo viário }\end{array}$ & IEcon2 & $25 \%$ & $20 \%$ & $20 \%$ & $15 \%$ & $40 \%$ & $20 \%$ & $20 \%$ & $10 \%$ & $20 \%$ & $21,10 \%$ \\
\hline $\begin{array}{l}\text { Percentual de ciclistas que } \\
\text { se beneficiaram dos efeitos } \\
\text { positivos indiretos gerados } \\
\text { pela ciclovia como aquisição } \\
\text { de emprego, educação e } \\
\text { outras oportunidades }\end{array}$ & IEcon3 & $25 \%$ & $30 \%$ & $30 \%$ & $10 \%$ & $10 \%$ & $35 \%$ & $20 \%$ & $40 \%$ & $20 \%$ & $24,50 \%$ \\
\hline $\begin{array}{l}\text { Percentual de ciclistas que } \\
\text { obtiveram redução de gastos } \\
\text { devido à utilização da ciclovia }\end{array}$ & IEcon4 & $25 \%$ & $40 \%$ & $30 \%$ & $60 \%$ & $20 \%$ & $40 \%$ & $40 \%$ & $40 \%$ & $30 \%$ & $36,10 \%$ \\
\hline $\begin{array}{l}\text { Variação anual da quantidade } \\
\text { de ciclistas mortos em } \\
\text { acidentes na região da ciclovia } \\
\text { por habitante por ano }\end{array}$ & IEcons & $100 \%$ & $100 \%$ & $100 \%$ & $100 \%$ & $100 \%$ & $100 \%$ & $100 \%$ & $100 \%$ & $100 \%$ & $100 \%$ \\
\hline $\begin{array}{l}\text { Redução do custo anual } \\
\text { de poluentes devido à } \\
\text { transferência de viagens } \\
\text { motorizadas para o modo } \\
\text { ciclo viário }\end{array}$ & IEcon6 & $100 \%$ & $100 \%$ & $100 \%$ & $100 \%$ & $100 \%$ & $100 \%$ & $100 \%$ & $100 \%$ & $100 \%$ & $100 \%$ \\
\hline $\begin{array}{l}\text { Redução de emissão de } \\
\text { poluentes de gases de efeito } \\
\text { estufa }\end{array}$ & IEnv1 & $50 \%$ & $30 \%$ & $50 \%$ & $50 \%$ & $50 \%$ & $40 \%$ & $50 \%$ & $40 \%$ & $30 \%$ & $43,30 \%$ \\
\hline $\begin{array}{l}\text { Redução de emissão de } \\
\text { poluentes locais }\end{array}$ & IEnv2 & $50 \%$ & $70 \%$ & $50 \%$ & $50 \%$ & $50 \%$ & $60 \%$ & $50 \%$ & $60 \%$ & $70 \%$ & $56,70 \%$ \\
\hline $\begin{array}{l}\text { Redução do nível de pressão } \\
\text { sonora proveniente da } \\
\text { transferência de viagens } \\
\text { motorizadas para o modo } \\
\text { ciclo viário }\end{array}$ & IEnv3 & $100 \%$ & $100 \%$ & $100 \%$ & $100 \%$ & $100 \%$ & $100 \%$ & $100 \%$ & $100 \%$ & $100 \%$ & $100 \%$ \\
\hline Promoção de áreas verdes & IEnv4 & $40 \%$ & $25 \%$ & $25 \%$ & $20 \%$ & $10 \%$ & $5 \%$ & $20 \%$ & $20 \%$ & $10 \%$ & $19,40 \%$ \\
\hline $\begin{array}{l}\text { Qualidade das áreas nas } \\
\text { imediações da ciclovia em } \\
\text { termos de não abandono e } \\
\text { degradação }\end{array}$ & IEnv5 & $15 \%$ & $25 \%$ & $25 \%$ & $30 \%$ & $30 \%$ & $20 \%$ & $20 \%$ & $20 \%$ & $20 \%$ & $22,80 \%$ \\
\hline $\begin{array}{l}\text { Compatibilidade da ciclovia } \\
\text { com o uso e ocupação do solo } \\
\text { e com a legislação em vigor }\end{array}$ & IEnv6 & $40 \%$ & $40 \%$ & $25 \%$ & $30 \%$ & $50 \%$ & $60 \%$ & $50 \%$ & $50 \%$ & $40 \%$ & $42,80 \%$ \\
\hline $\begin{array}{l}\text { Intensidade de danos } \\
\text { causados ao meio ambiente } \\
\text { devido à construção ou } \\
\text { restauração da ciclovia }\end{array}$ & IEnv7 & $5 \%$ & $10 \%$ & $25 \%$ & $20 \%$ & $10 \%$ & $15 \%$ & $10 \%$ & $10 \%$ & $30 \%$ & $15 \%$ \\
\hline
\end{tabular}

Semelhantemente aos pesos do nível hierárquico anterior, os pesos dos Indicadores foram ponderados, multiplicados pelos pesos de suas respectivas Características (apresentados nas Quadros 2 a 4). Os valores ponderados resultantes para todos os níveis hierárquicos estão apresentados na Quadro 6. 
Quadro 6. Descrição e peso das Dimensões, Características, Indicadores do modelo de Sustentabilidade de Ciclovias, com valores ponderados. Fonte: Autores.

\begin{tabular}{|c|c|c|c|c|c|c|}
\hline Dimensão & Característica & Indicador & Variável & $\begin{array}{l}\text { Peso do } \\
\text { Indicador }\end{array}$ & $\begin{array}{l}\text { Peso da } \\
\text { Característica }\end{array}$ & $\begin{array}{l}\text { Peso da } \\
\text { Dimensão }\end{array}$ \\
\hline \multirow{15}{*}{. } & \multirow{5}{*}{$\begin{array}{l}\text { Promoção de } \\
\text { acessibilidade e } \\
\text { integração com } \\
\text { sistemas de } \\
\text { transporte público }\end{array}$} & Volume de bicicletas na ciclovia & ISoc1 & 0.0324 & \multirow[t]{5}{*}{0.1572} & \multirow[t]{15}{*}{0.393} \\
\hline & & $\begin{array}{l}\text { Existência de áreas comerciais e } \\
\text { unidades de ensino dentro de uma } \\
\text { distância de } 500 \text { metros da ciclovia }\end{array}$ & ISoc2 & 0.0287 & & \\
\hline & & $\begin{array}{l}\text { Percentual de viagens de ciclistas } \\
\text { por motivo de trabalho ou estudo }\end{array}$ & ISoc3 & 0.0365 & & \\
\hline & & $\begin{array}{l}\text { Disponibilidade de } \\
\text { estacionamentos de bicicletas } \\
\text { junto à ciclovia }\end{array}$ & ISoc4 & 0.0247 & & \\
\hline & & Integração intermodal & ISocs & 0.0349 & & \\
\hline & \multirow{7}{*}{$\begin{array}{l}\text { Promoção de } \\
\text { segurança durante } \\
\text { a mobilidade dos } \\
\text { ciclistas }\end{array}$} & $\begin{array}{l}\text { Percepção do ciclista com relação a } \\
\text { furtos e roubos na ciclovia }\end{array}$ & ISoc6 & 0.0203 & \multirow[t]{7}{*}{0.1639} & \\
\hline & & $\begin{array}{l}\text { Frequência de policiamento nas } \\
\text { imediações da ciclovia }\end{array}$ & 1 Soc7 & 0.0203 & & \\
\hline & & $\begin{array}{l}\text { Localização espacial e } \\
\text { conectividade com outras ciclovias }\end{array}$ & ISoc8 & 0.0275 & & \\
\hline & & $\begin{array}{l}\text { Qualidade da sinalização da } \\
\text { ciclovia. dos cruzamentos ciclo } \\
\text { viários e do tratamento dos locais } \\
\text { críticos }\end{array}$ & ISoc9 & 0.0338 & & \\
\hline & & $\begin{array}{l}\text { Qualidade do pavimento da } \\
\text { ciclovia }\end{array}$ & ISoc10 & 0.0197 & & \\
\hline & & Qualidade da drenagem da ciclovia & ISoc11 & 0.0157 & & \\
\hline & & $\begin{array}{l}\text { Disponibilização de iluminação } \\
\text { pública nos arredores da ciclovia }\end{array}$ & ISoc12 & 0.0266 & & \\
\hline & \multirow{3}{*}{$\begin{array}{l}\text { Promoção de saúde } \\
\text { e lazer }\end{array}$} & Promoção de saúde & ISoc13 & 0.0203 & \multirow[t]{3}{*}{0.0719} & \\
\hline & & Promoção de atividade de lazer & ISoc14 & 0.0188 & & \\
\hline & & $\begin{array}{l}\text { Promoção de qualidade de vida e } \\
\text { redução do nível de estresse dos } \\
\text { ciclistas }\end{array}$ & ISoc15 & 0.0328 & & \\
\hline \multirow{6}{*}{ 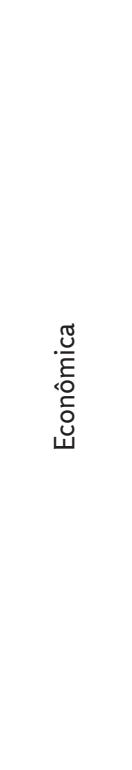 } & \multirow[t]{4}{*}{$\begin{array}{l}\text { Promoção de } \\
\text { equidade }\end{array}$} & $\begin{array}{l}\text { Percentual de ciclistas que não } \\
\text { possuem veículo particular }\end{array}$ & IEcon1 & 0.0182 & \multirow[t]{4}{*}{0.0996} & \multirow[t]{6}{*}{0.276} \\
\hline & & $\begin{array}{l}\text { Percentual de transferência do } \\
\text { modo a pé para o ciclo viário }\end{array}$ & IEcon2 & 0.0201 & & \\
\hline & & $\begin{array}{l}\text { Percentual de ciclistas que se } \\
\text { beneficiaram dos efeitos positivos } \\
\text { indiretos gerados pela ciclovia } \\
\text { como aquisição de emprego. } \\
\text { educação e outras oportunidades }\end{array}$ & IEcon3 & 0.0244 & & \\
\hline & & $\begin{array}{l}\text { Percentual de ciclistas que } \\
\text { obtiveram redução de gastos } \\
\text { devido à utilização da ciclovia }\end{array}$ & IEcon4 & 0.0360 & & \\
\hline & $\begin{array}{l}\text { Redução de custos } \\
\text { provenientes de } \\
\text { acidentes com } \\
\text { ciclistas na região }\end{array}$ & $\begin{array}{l}\text { Variação anual da quantidade de } \\
\text { ciclistas mortos em acidentes na } \\
\text { região da ciclovia por habitante } \\
\text { por ano }\end{array}$ & IEcons & 0.0996 & 0.0996 & \\
\hline & $\begin{array}{l}\text { Redução de custo de } \\
\text { poluição atmosférica }\end{array}$ & $\begin{array}{l}\text { Redução do custo anual de } \\
\text { poluentes devido à transferência } \\
\text { de viagens motorizadas para o } \\
\text { modo ciclo viário }\end{array}$ & IEcon6 & 0.0768 & 0.0768 & \\
\hline
\end{tabular}




\begin{tabular}{|c|c|c|c|c|c|c|}
\hline \multirow{7}{*}{ 苾 } & \multirow{2}{*}{$\begin{array}{l}\text { Redução de emissões } \\
\text { de poluentes } \\
\text { atmosféricos }\end{array}$} & $\begin{array}{l}\text { Redução de emissão de poluentes } \\
\text { de gases de efeito estufa }\end{array}$ & IEnv1 & 0.0563 & \multirow[t]{2}{*}{0.1300} & \multirow[t]{7}{*}{0.331} \\
\hline & & $\begin{array}{l}\text { Redução de emissão de poluentes } \\
\text { locais }\end{array}$ & IEnv2 & 0.0737 & & \\
\hline & $\begin{array}{l}\text { Redução do nível de } \\
\text { pressão sonora }\end{array}$ & $\begin{array}{l}\text { Redução do nível de pressão } \\
\text { sonora proveniente da } \\
\text { transferência de viagens } \\
\text { motorizadas para o modo ciclo } \\
\text { viário }\end{array}$ & IEnv3 & 0.0639 & 0.0639 & \\
\hline & \multirow{4}{*}{$\begin{array}{l}\text { Requalificação } \\
\text { urbana e minimização } \\
\text { de danos ao meio } \\
\text { ambiente }\end{array}$} & Promoção de áreas verdes & IEnv4 & 0.0266 & \multirow[t]{4}{*}{0.1371} & \\
\hline & & $\begin{array}{l}\text { Qualidade das áreas nas } \\
\text { imediações da ciclovia em termos } \\
\text { de não abandono e degradação }\end{array}$ & IEnvs & 0.0312 & & \\
\hline & & $\begin{array}{l}\text { Compatibilidade da ciclovia com } \\
\text { o uso e ocupação do solo e com a } \\
\text { legislação em vigor }\end{array}$ & IEnv6 & 0.0587 & & \\
\hline & & $\begin{array}{l}\text { Intensidade de danos causados } \\
\text { ao meio ambiente devido à } \\
\text { construção ou restauração da } \\
\text { ciclovia }\end{array}$ & IEnv7 & 0.0206 & & \\
\hline
\end{tabular}

Considerando os valores atribuídos para as Dimensões, Características e Indicadores, pode-se rescrever a Eq. 7 como:

$$
\begin{aligned}
S I=(0.0324 \times & \left.I_{\text {soc } 1}\right)+\left(0.0287 \times I_{\text {soc } 2}\right)+\left(0.0365 \times I_{\text {soc } 3}\right)+\left(0.0247 \times I_{\text {soc } 4}\right)+\left(0.0349 \times I_{\text {soc } 5}\right) \\
& +\left(0.0203 \times I_{\text {soc } 6}\right)+\left(0.0203 \times I_{\text {soc } 7}\right)+\left(0.0275 \times I_{\text {soc } 8}\right)+\left(0.0338 \times I_{\text {soc } 9}\right) \\
& +\left(0.0197 \times I_{\text {soc } 10}\right)+\left(0.0157 \times I_{\text {soc } 11}\right)+\left(0.0266 \times I_{\text {soc } 12}\right)+\left(0.0203 \times I_{\text {soc } 13}\right) \\
& +\left(0.0188 \times I_{\text {soc } 14}\right)+\left(0.0328 \times I_{\text {soc } 15}\right)+\left(0.0182 \times I_{\text {Econ } 1}\right)+\left(0.0201 \times I_{\text {Econ } 2}\right) \\
& +\left(0.0244 \times I_{\text {Econ } 3}\right)+\left(0.0360 \times I_{\text {Econ } 4}\right)+\left(0.0996 \times I_{\text {Econ } 5}\right)+\left(0.0768 \times I_{\text {Econ } 6}\right) \\
& +\left(0.0563 \times I_{\text {Env } 1}\right)+\left(0.0737 \times I_{\text {Env } 2}\right)+\left(0.0639 \times I_{\text {Env } 3}\right)+\left(0.0266 \times I_{\text {Env } 4}\right) \\
& +\left(0.0312 \times I_{\text {Env } 5}\right)+\left(0.0587 \times I_{\text {Env } 6}\right)+\left(0.0206 \times I_{\text {Env } 7}\right) \\
& (\text { Eq. 13) }
\end{aligned}
$$

(Eq. 13)

\section{Aplicação do modelo para avaliação da sustentabilidade em duas ciclovias}

O modelo desenvolvido no presente trabalho foi aplicado em duas ciclovias do Distrito Federal, Brasil. Uma ciclovia localizada na região Norte e outra na região Oeste da cidade. A escolha das duas ciclovias avaliadas (Figura 3), levou em consideração a demanda de viagens na região, a localização da ciclovia considerando ser um eixo de transporte (main axis of circulation), a densidade habitacional da região, o fluxo de bicicletas da ciclovia e o fluxo de automóveis nas vias paralelas à ciclovia. A localização dos pontos de amostragem e características dos trechos estudados nas duas ciclovias, são mostrados no Quadro 7. 


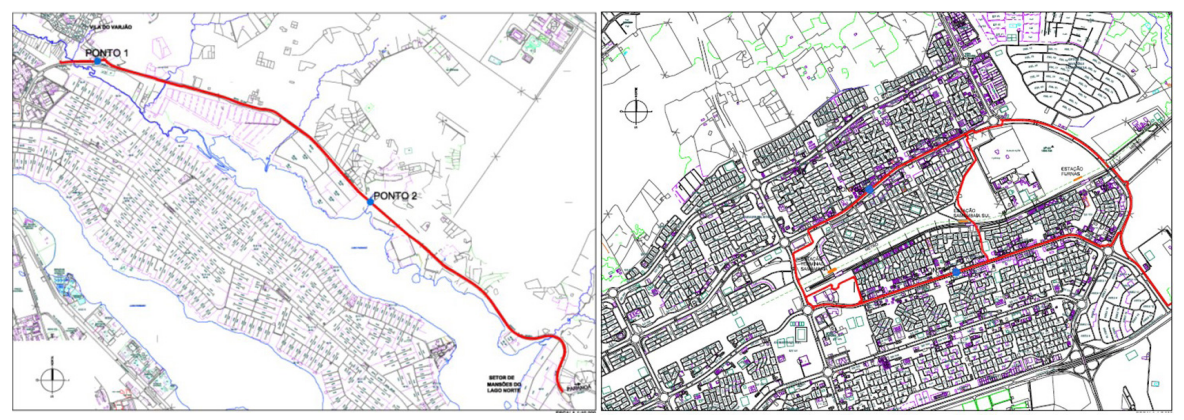

Figura 3. Ciclovias avaliadas e os pontos de amostragem. Fonte: Miranda (2012).

Quadro 7. Localização dos pontos de amostragem e características dos trechos das Ciclovias. Fonte: Autores.

\begin{tabular}{|l|l|l|c|c|}
\hline & Ponto 1 & Ponto 2 & $\begin{array}{l}\text { Fluxo médio } \\
\text { de Bicicletas } \\
\text { /dia) }\end{array}$ & Comprimento (km) \\
\hline Ciclovia 1 & $\begin{array}{l}15^{\circ} 42^{\prime} 53.18^{\prime \prime} \mathrm{S} \\
47^{\circ} 52^{\prime} 29.06 \text { "W }\end{array}$ & $\begin{array}{l}15^{\circ} 43^{\prime} 56.2 " \mathrm{~S} \\
47^{\circ} 50^{\prime} 20.5^{\prime \prime} \mathrm{W}\end{array}$ & 236.4 & 9.8 \\
\hline Ciclovia 2 & $\begin{array}{l}1^{\circ} 52^{\prime} 25.5^{\prime \prime} \mathrm{S} \\
48^{\circ} \mathrm{O} 4^{\prime} 23.7^{\prime \prime} \mathrm{W}\end{array}$ & $\begin{array}{l}15^{\circ} 51^{\prime} 55.9^{\prime \prime} \mathrm{S} \\
48^{\circ} 04^{\prime} 53.7^{\prime \prime} \mathrm{W}\end{array}$ & 525.5 & 13 \\
\hline
\end{tabular}

Os valores do Fluxo médio de Bicicletas, no Quadro 9, foram medidos como parte do estudo de campo do presente trabalho, escolhidos dois pontos de contagem nas duas ciclovias, indicados na Figura 2 e coordenadas geográfica no Quadro 9. O Fluxo de bicicletas por dia, na ciclovia, foi a média das contagens dos dois pontos e não considerou os ciclistas que circularam fora da ciclovia. Os pesquisadores selecionados para as contagens, foram treinados para realizar as contagens e após o treinamento, dois pesquisadores se posicionaram para cada ponto da ciclovia. Um grupo aplicou a pesquisa de 6 às 13 horas e outro grupo aplicou a pesquisa de 13 às 20 horas, simultaneamente nos dois pontos.

Para a avaliação da sustentabilidade das ciclovias, com base no modelo proposto neste trabalho, foram realizadas entrevistas aos usuários das ciclovias, aplicadas pelos mesmos pesquisadores posicionados nos pontos citados anteriormente. As entrevistas foram feitas durante 4 dias da semana, entre as 6 h00 e 20h00, e os usuários atribuíram notas (Scores) entre 0 e 1 aos indicadores propostos. Foram entrevistados 148 usuários na ciclovia 1, e 293 usuários na ciclovia 2.

\section{Resultados}

As notas (Scores) para avaliação dos indicadores, foram normalizadas em uma escala de 0 a 1 . Durante as entrevistas, foram feitas perguntas aos usuários das ciclovias, e esses usuários atribuíram notas aos indicadores. Porém, as notas (scores) dos indicadores $I_{\text {Soc1 }}, I_{\text {Soc2 } 2}, I_{\text {Econ } 5}, I_{\text {Econ6 }}, I_{E n v 1}, I_{\text {Env2 }}, I_{E n v 6}$ e $I_{E n v 7}$ foram determinadas diretamente dos dados fornecidos pelas instituiçốes públicas de saúde e mobilidade. O Quadro 8 apresenta as notas dos indicadores, bem como, a correspondência entre as unidades dos indicadores e a escala entre 0 e 1 . 
Quadro 8. Notas dos indicadores e unidades correspondentes à escala entre o e 1.

\begin{tabular}{|c|c|c|c|c|c|c|c|}
\hline \multirow[t]{2}{*}{ Indicadores } & \multicolumn{2}{|c|}{$\begin{array}{l}\text { Pontuação - valores } \\
\text { atribuídos por } \\
\text { entrevistas locais } \\
\text { referidas como as } \\
\text { condições da ciclovia }\end{array}$} & \multicolumn{5}{|c|}{ Escala de Pontuação } \\
\hline & Ciclovia 1 & Ciclovia 2 & 1 & 0,75 & 0,5 & 0,25 & o \\
\hline & $\begin{array}{l}148 \\
\text { (Tamanho } \\
\text { da } \\
\text { amostra) }\end{array}$ & $\begin{array}{l}293 \\
\text { (Tamanho } \\
\text { da } \\
\text { amostra) }\end{array}$ & & & & & \\
\hline ISoc1 & 0,25 & 0,5 & $\begin{array}{l}\text { Quantidade de } \\
\text { fluxo diário de } \\
\text { passageiros (I } \\
\geq 7000 \text { ) }\end{array}$ & $\begin{array}{l}\text { Quantidade } \\
\text { de fluxo diário } \\
\text { de passageiros } \\
(7000>I \geq 3000)\end{array}$ & $\begin{array}{l}\text { Quantidade } \\
\text { de fluxo diário } \\
\text { de passageiros } \\
(3000>\mid \geq 500)\end{array}$ & $\begin{array}{l}\text { Quantidade } \\
\text { de fluxo diário } \\
\text { de passageiros } \\
(500>\mid \geq 100)\end{array}$ & $\begin{array}{l}\text { Quantidade de } \\
\text { fluxo diário de } \\
\text { passageiros (I } \\
\leq 100 \text { ) }\end{array}$ \\
\hline ISoc2 & 0,5 & 1 & Altíssimo & Alto & Médio & Baixo & Baixíssimo \\
\hline ISoc3 & 0,75 & 0,5 & $I \geq 80 \%$ & $80 \%>1 \geq 60 \%$ & $60 \%>1 \geq 40 \%$ & $40 \%>I \geq 20 \%$ & I $\leq 20 \%$ \\
\hline ISoc4 & 0,25 & 0,25 & Excelente & Bom & Médio & Razoável & Pobre \\
\hline ISoc5 & o & 0,75 & Excelente & Bom & Médio & Razoável & Pobre \\
\hline ISoc6 & 0,25 & 0,5 & Baixíssimo & Baixo & Médio & Alto & Altíssimo \\
\hline ISoc7 & 0,5 & 0,25 & Excelente & Bom & Médio & Razoável & Pobre \\
\hline ISoc8 & 0,25 & 0,75 & Excelente & Bom & Médio & Razoável & Pobre \\
\hline ISoc9 & 0,5 & 0,75 & Excelente & Bom & Médio & Razoável & Pobre \\
\hline ISoc10 & 0,75 & 0,75 & Excelente & Bom & Médio & Razoável & Pobre \\
\hline ISoc11 & 0,75 & 0,75 & Excelente & Bom & Médio & Razoável & Pobre \\
\hline ISoc12 & 0,75 & 0,75 & Excelente & Bom & Médio & Razoável & Pobre \\
\hline ISoc13 & 1 & 1 & $\begin{array}{l}\text { Quantidade } \\
\text { de passageiros } \\
\text { que pedalam } \\
\text { pelo menos } \\
15 \mathrm{~min} / \mathrm{dia}(\mathrm{l} \geq \\
80 \%)\end{array}$ & $\begin{array}{l}\text { Quantidade } \\
\text { de passageiros } \\
\text { que pedalam } \\
\text { pelo menos } 15 \\
\text { min/dia(80\%> I } \\
\geq 60 \%)\end{array}$ & $\begin{array}{l}\text { Quantidade } \\
\text { de passageiros } \\
\text { que pedalam } \\
\text { pelo menos } 15 \\
\text { min/dia(6o\%> I } \\
\geq 40 \%)\end{array}$ & $\begin{array}{l}\text { Quantidade } \\
\text { de passageiros } \\
\text { que pedalam } \\
\text { pelo menos } 15 \\
\mathrm{~min} / \text { dia(40\%> I } \\
\geq 20 \% \text { ) }\end{array}$ & $\begin{array}{l}\text { Quantidade de } \\
\text { passageiros que } \\
\text { pedalam pelo } \\
\text { menos } 15 \mathrm{~min} / \\
\text { dia(l } \leq 20 \%)\end{array}$ \\
\hline ISoc14 & 0,75 & 1 & $\begin{array}{l}\text { Porcentagem } \\
\text { de viagens de } \\
\text { bicicleta para } \\
\text { fins de lazer ( } \geq \\
80 \% \text { ) }\end{array}$ & $\begin{array}{l}\text { Porcentagem } \\
\text { de viagens de } \\
\text { bicicleta para } \\
\text { fins de lazer } \\
(80 \%>I \geq 60 \%)\end{array}$ & $\begin{array}{l}\text { Porcentagem } \\
\text { de viagens de } \\
\text { bicicleta para } \\
\text { fins de lazer } \\
(60 \%>1 \geq 40 \%)\end{array}$ & $\begin{array}{l}\text { Porcentagem } \\
\text { de viagens de } \\
\text { bicicleta para } \\
\text { fins de lazer } \\
(40 \%>I \geq 20 \%)\end{array}$ & $\begin{array}{l}\text { Porcentagem } \\
\text { de viagens de } \\
\text { bicicleta para } \\
\text { fins de lazer (I } \\
\leq \mathbf{2 0 \% )}\end{array}$ \\
\hline ISoc15 & 0,75 & 1 & Excelente & Bom & Médio & Razoável & Pobre \\
\hline IEcon1 & 0,75 & 0,75 & $\begin{array}{l}\text { Porcentagem } \\
\text { de ciclistas } \\
\text { que possuem } \\
\text { carros(I } \leq 20 \%)\end{array}$ & $\begin{array}{l}\text { Porcentagem } \\
\text { de ciclistas } \\
\text { que possuem } \\
\text { carros(40\%> I } \\
\geq 20 \%)\end{array}$ & $\begin{array}{l}\text { Porcentagem } \\
\text { de ciclistas } \\
\text { que possuem } \\
\text { carros(6o\%> I } \\
\geq 40 \%)\end{array}$ & $\begin{array}{l}\text { Porcentagem } \\
\text { de ciclistas que } \\
\text { possuem carros } \\
(80 \%>I \geq 60 \%)\end{array}$ & $\begin{array}{l}\text { Porcentagem } \\
\text { de ciclistas que } \\
\text { possuem carros( } \\
\mathrm{I} \geq 80 \% \text { ) }\end{array}$ \\
\hline IEcon2 & 1 & 1 & $\begin{array}{l}\text { Mudança } \\
\text { modal - } \\
\text { Passeios a pé } \\
\text { de bicicleta(l } \\
\geq 10 \% \text { do total } \\
\text { de viagens) }\end{array}$ & - & $\begin{array}{l}\text { Mudança } \\
\text { modal - Passeios } \\
\text { a pé de } \\
\text { bicicleta(10\%> I } \\
\geq 1 \% \text { do total de } \\
\text { viagens) }\end{array}$ & - & $\begin{array}{l}\text { Mudança modal } \\
\text { - Passeios a pé } \\
\text { de bicicleta(I< } \\
1 \% \text { do total de } \\
\text { viagens) }\end{array}$ \\
\hline
\end{tabular}




\begin{tabular}{|c|c|c|c|c|c|c|c|}
\hline IEcon3 & 1 & 1 & $\begin{array}{l}\text { Porcentagem } \\
\text { de ciclistas que } \\
\text { se beneficiam } \\
\text { do impacto } \\
\text { positivo da } \\
\text { ciclovia (I } \\
\geq 10 \% \text { do total } \\
\text { de ciclistas) }\end{array}$ & - & $\begin{array}{l}\text { Porcentagem de } \\
\text { ciclistas que se } \\
\text { beneficiam do } \\
\text { impacto positivo } \\
\text { da ciclovia } \\
(10 \%>I \geq 1 \% \text { do } \\
\text { total de ciclistas) }\end{array}$ & - & $\begin{array}{l}\text { Porcentagem de } \\
\text { ciclistas que se } \\
\text { beneficiam do } \\
\text { impacto positivo } \\
\text { da ciclovia (I < } \\
1 \% \text { do total de } \\
\text { ciclistas) }\end{array}$ \\
\hline IEcon4 & 1 & 1 & $\begin{array}{l}\text { Porcentagem } \\
\text { de usuários de } \\
\text { bicicleta que } \\
\text { se beneficiam } \\
\text { de despesas } \\
\text { mensais } \\
\text { reduzidas (l } \geq \\
10 \%)\end{array}$ & $\begin{array}{l}\text { Porcentagem } \\
\text { de usuários de } \\
\text { bicicleta que } \\
\text { se beneficiam } \\
\text { de despesas } \\
\text { mensais } \\
\text { reduzidas } \\
(10 \%>1 \geq 6 \%)\end{array}$ & $\begin{array}{l}\text { Porcentagem } \\
\text { de usuários de } \\
\text { bicicleta que } \\
\text { se beneficiam } \\
\text { de despesas } \\
\text { mensais } \\
\text { reduzidas (6\%> } \\
\mid \geq 3 \% \text { ) }\end{array}$ & $\begin{array}{l}\text { Porcentagem } \\
\text { de usuários de } \\
\text { bicicleta que } \\
\text { se beneficiam } \\
\text { de despesas } \\
\text { mensais } \\
\text { reduzidas (o\%> } \\
\text { I >3\%) }\end{array}$ & $\begin{array}{l}\text { Porcentagem } \\
\text { de usuários de } \\
\text { bicicleta que } \\
\text { se beneficiam } \\
\text { de despesas } \\
\text { mensais } \\
\text { reduzidas ( I= } \\
\text { ०\%) }\end{array}$ \\
\hline IEcons & o & 1 & 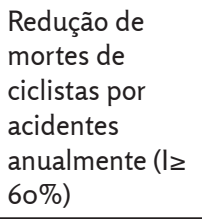 & $\begin{array}{l}\text { Redução de } \\
\text { mortes de } \\
\text { ciclistas por } \\
\text { acidentes } \\
\text { anualmente } \\
(60 \%>I \geq 40 \%)\end{array}$ & $\begin{array}{l}\text { Redução de } \\
\text { mortes de } \\
\text { ciclistas por } \\
\text { acidentes } \\
\text { anualmente } \\
(40 \%>1 \geq 20 \%)\end{array}$ & $\begin{array}{l}\text { Redução de } \\
\text { mortes de } \\
\text { ciclistas por } \\
\text { acidentes } \\
\text { anualmente } \\
(20 \%>1>0 \%)\end{array}$ & $\begin{array}{l}\text { Redução de } \\
\text { mortes de } \\
\text { ciclistas por } \\
\text { acidentes } \\
\text { anualmente ( I= } \\
\text { o\%) }\end{array}$ \\
\hline IEcon6 & 0,25 & 0,75 & $\begin{array}{l}\text { Redução de } \\
\text { custos anuais } \\
\text { devido à } \\
\text { poluição do } \\
\text { ar (I } \geq \text { BRL } \\
22.282,00)\end{array}$ & $\begin{array}{l}\text { Redução de } \\
\text { custos anuais } \\
\text { devido à } \\
\text { poluição do ar } \\
\text { (BRL 22.282,o0> } \\
\text { I } \geq \text { BRL } \\
14.487,00 \text { ) }\end{array}$ & $\begin{array}{l}\text { Redução de } \\
\text { custos anuais } \\
\text { devido à } \\
\text { poluição do ar } \\
\text { (BRL } 9.658,00>\text { I } \\
\geq \text { BRL } 14.487,00 \text { ) }\end{array}$ & $\begin{array}{l}\text { Redução de } \\
\text { custos anuais } \\
\text { devido à } \\
\text { poluição do ar } \\
\text { (BRL } 9.658,00>\text { I } \\
\text { >BRL } 5.795,00 \text { ) }\end{array}$ & $\begin{array}{l}\text { Redução de } \\
\text { custos anuais } \\
\text { devido à } \\
\text { poluição do ar (I } \\
\text { <BRL 5.795,00) }\end{array}$ \\
\hline IEnv1 & 0,25 & 0,75 & $\begin{array}{l}\text { Redução das } \\
\text { emissões } \\
\text { anuais de GEE } \\
\text { em toneladas } \\
\text { de COzeq ( } \geq \\
123,35 \text { ) }\end{array}$ & $\begin{array}{l}\text { Redução das } \\
\text { emissões anuais } \\
\text { de GEE em } \\
\text { toneladas de } \\
\text { CO2eq }(88,10>\text { I } \\
\geq 123,35)\end{array}$ & $\begin{array}{l}\text { Redução das } \\
\text { emissões anuais } \\
\text { de GEE em } \\
\text { toneladas de } \\
\text { COzeq }(58,73>\text { I } \\
\geq 88,10)\end{array}$ & $\begin{array}{l}\text { Redução das } \\
\text { emissões anuais } \\
\text { de GEE em } \\
\text { toneladas de } \\
\text { CO2eq }(35,24 \geq 1 \\
>58,73)\end{array}$ & $\begin{array}{l}\text { Redução das } \\
\text { emissões anuais } \\
\text { de GEE em } \\
\text { toneladas de } \\
\text { CO2eq }(\mathrm{I}<35,24)\end{array}$ \\
\hline IEnv2 & 0,25 & 0,75 & $\begin{array}{l}\text { Redução das } \\
\text { emissões locais } \\
\text { anuais de } \\
\text { poluentes em } \\
\text { toneladas ( } \geq \\
1,26)\end{array}$ & $\begin{array}{l}\text { Redução das } \\
\text { emissões } \\
\text { locais anuais } \\
\text { de poluentes } \\
\text { em toneladas } \\
(0,90>\mid \geq 1,26)\end{array}$ & $\begin{array}{l}\text { Redução das } \\
\text { emissões locais } \\
\text { anuais de } \\
\text { poluentes em } \\
\text { toneladas (o,62> } \\
\text { I } \geq 0,90 \text { ) }\end{array}$ & 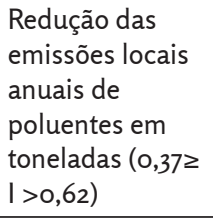 & $\begin{array}{l}\text { Redução das } \\
\text { emissões locais } \\
\text { anuais de } \\
\text { poluentes em } \\
\text { toneladas (I } \\
<0,37 \text { ) }\end{array}$ \\
\hline IEnv3 & 0,5 & 0,5 & Excelente & Bom & Médio & Razoável & Pobre \\
\hline IEnv4 & 0,75 & 0,75 & Excelente & Bom & Médio & Razoável & Pobre \\
\hline IEnv5 & 1 & 1 & Excelente & Bom & Médio & Razoável & Pobre \\
\hline IEnv6 & 1 & 1 & Excelente & Bom & Médio & Razoável & Pobre \\
\hline IEnv7 & 1 & 1 & $\begin{array}{l}\text { Sem impactos } \\
\text { significativos }\end{array}$ & - & $\begin{array}{l}\text { Impactos } \\
\text { menores }\end{array}$ & - & $\begin{array}{l}\text { Impactos } \\
\text { significativos }\end{array}$ \\
\hline
\end{tabular}

Como um primeiro resultado agregado, aplicou-se as notas (scores) dos indicadores do Quadro 8 na Eq. 4, obtendo um Îndice de Sustentabilidade (SI) de 0.50965 para ciclovia 1 e 0.78725 para a ciclovia 2. O Quadro 9 apresenta os valores calculados do SI para as duas ciclovias e os valores para cada Dimensão de Sustentabilidade. Comparando o SI global das duas ciclovias, pode-se assumir em primeira análise, que a ciclovia 2 seria mais sustentável que a ciclovia 1 . Ao mesmo tempo, o resultado das Dimensões de Sustentabilidade indica que a ciclovia 2 tem valores maiores e com menor dispersão, entre 0.25 e 0.27 , já a ciclovia 1 tem valores menores e maior dispersão, entre 0.11 e 0.20 . Ao mesmo tempo, a ciclovia 1 apresenta ligeiramente menor valor de sustentabilidade na Dimensão Econômica, quando comparada à ciclovia 2. 
Quadro 9. Índice de Sustentabilidade (SI) calculado para as duas ciclovias avaliadas (Fonte: Autores).

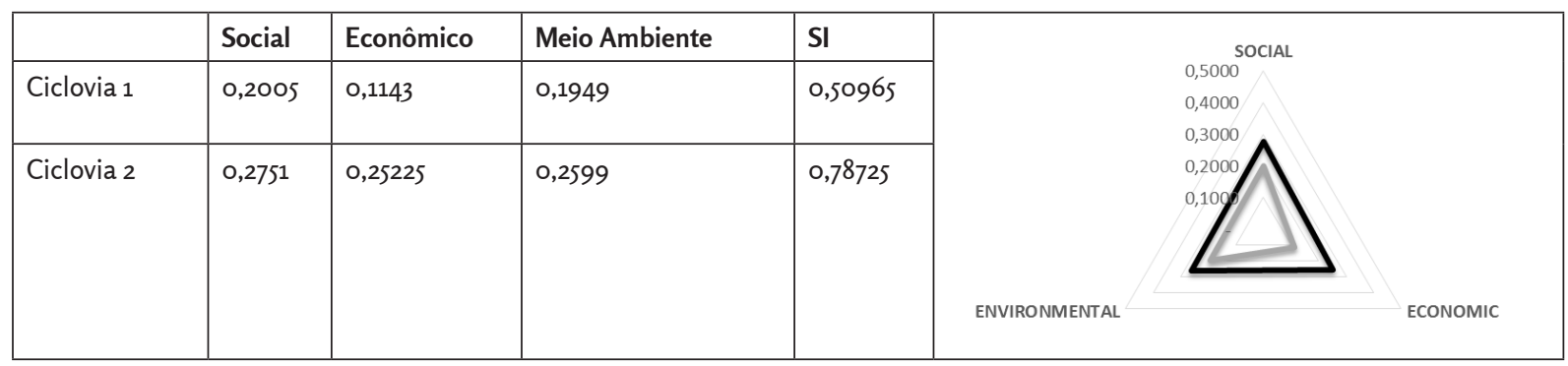

Com o objetivo de testar a sensibilidade do modelo quanto à influência dos pesos dos indicadores no resultado final do SI, foi estabelecido um mesmo peso para todos os indicadores. Atribuiu-se um valor constante de peso para cada Indicador desde a soma de todos os pesos fosse 1 (ou 100\%). O peso de cada indicador passou a ser de 0,03571. O resultado apresentado no Quadro 10 mostra que, quando os Indicadores têm o mesmo peso, o Índice de Sustentabilidade (SI) da ciclovia 1 passa a ser de 0,59821 e o da ciclovia 2 passa a ser de 0,77679 . O SI global das duas ciclovias não variou muito para esse caso, e novamente pode-se assumir que a ciclovia 2 seria mais sustentável que a ciclovia 1. Os resultados desagregados para as Dimensões de Sustentabilidade, mantém-se semelhantes ao que foi observado anteriormente, onde a ciclovia 2 tem valores maiores comparados aos valores da ciclovia $1 \mathrm{em}$ todas as Dimensões. Contudo, para esse caso há um aumento do grau de sustentabilidade da Dimensão Social para as duas ciclovias.

Quadro 10. Índice de Sustentabilidade (SI) calculado para as duas ciclovias avaliadas com pesos iguais dos indicadores. Fonte: Autores.

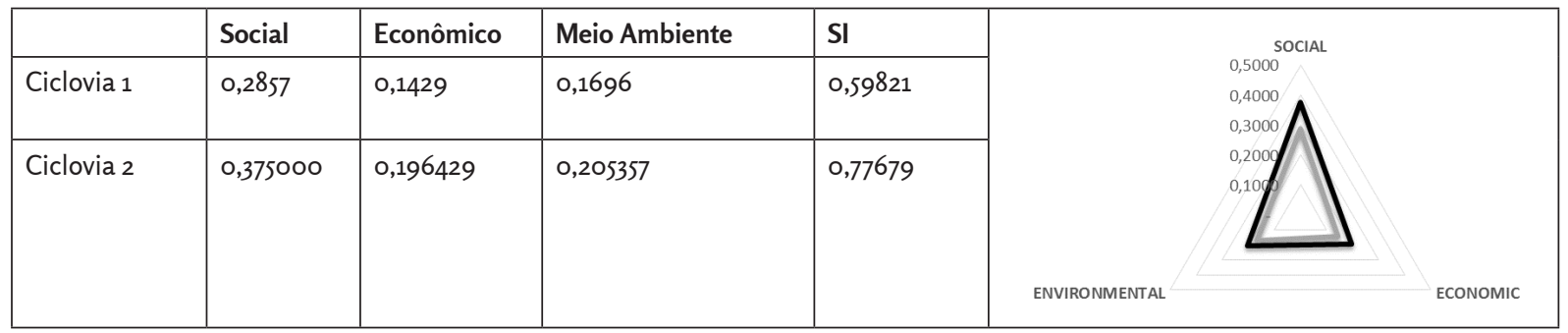

Uma outra análise foi realizada para testar a resposta do modelo com relação à influência dos pesos das Dimensões de Sustentabilidade no SI. Nesse caso, utilizou-se diretamente os valores atribuídos pelos especialistas na etapa de avaliação dos Indicadores, sem ponderar os pesos das Características e das Dimensões. Em seguida, foi estabelecido igualmente o mesmo peso 1 para cada Dimensão, e os pesos dos Indicadores foram assumidos como aqueles atribuídos pelos especialistas. Adicionalmente, os pesos dos Indicadores foram redimensionados para que a soma de todos os Indicadores fosse 1 (ou 100\%) dentro de cada Dimensão. A Eq. 13 foi então rescrita como Eq. 14:

$$
\begin{aligned}
S I=(0.06867 & \left.\times I_{\text {soc } 1}\right)+\left(0.06100 \times I_{\text {soc } 2}\right)+\left(0.07733 \times I_{\text {soc } 3}\right)+\left(0.05233 \times I_{\text {soc } 4}\right) \\
& +\left(0.07400 \times I_{\text {soc } 5}\right)+\left(0.04133 \times I_{\text {soc } 6}\right)+\left(0.04133 \times I_{\text {soc } 6}\right)+\left(0.05600 \times I_{\text {soc } 8}\right) \\
& +\left(0.06867 \times I_{\text {soc } 9}\right)+\left(0.04000 \times I_{\text {soc } 10}\right)+\left(0.03200 \times I_{\text {soc } 11}\right)+\left(0.05400 \times I_{\text {soc } 12}\right) \\
& +\left(0.09433 \times I_{\text {soc } 13}\right)+\left(0.08700 \times I_{\text {soc } 14}\right)+\left(0.1520 \times I_{\text {soc } 15}\right)+\left(0.06100 \times I_{\text {Econ } 1}\right) \\
& +\left(0.07033 \times I_{\text {Econ } 2}\right)+\left(0.08167 \times I_{\text {Econ } 3}\right)+\left(0.12033 \times I_{\text {Econ } 4}\right)+\left(0.3333 \times I_{\text {Econ } 5}\right) \\
& +\left(0.3333 \times I_{\text {Econ } 6}\right)+\left(0.14433 \times I_{\text {Env } 1}\right)+\left(0.18900 \times I_{\text {Env } 2}\right)+\left(0.3333 \times I_{\text {Env } 3}\right) \\
& +\left(0.06467 \times I_{\text {Env } 4}\right)+\left(0.07600 \times I_{\text {Env } 5}\right)+\left(0.14267 \times I_{\text {Env } 6}\right)+\left(0.0500 \times I_{\text {Env } 7}\right)
\end{aligned}
$$


Quadro 11. Índice de Sustentabilidade (SI) calculado para as duas ciclovias avaliadas com pesos iguais das Dimensões. Fonte: Autores.

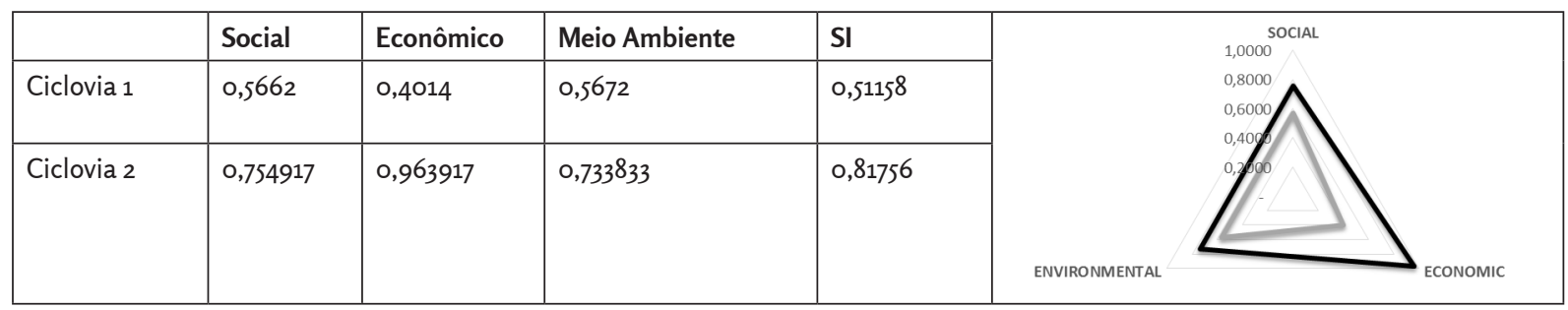

O resultado apresentado no Quadro 11 mostra que, quando as Dimensões têm o mesmo peso, o Índice de Sustentabilidade (SI) da ciclovia 1 passa a ser de 0.51158 e o da ciclovia 2 passa a ser de 0.81756 . Semelhantemente aos resultados anteriores, o SI global das duas ciclovias indica maior grau de sustentabilidade global para a ciclovia 2. Os resultados desagregados para as Dimensões de Sustentabilidade mantêm-se semelhantes ao que foi observado anteriormente, onde a ciclovia 2 tem valores maiores comparados aos valores da ciclovia 1. Entretanto, para esse caso, observa-se um aumento do grau de sustentabilidade na Dimensão Econômica.

\section{Conclusão}

O presente trabalho propôs um modelo quantitativo de sustentabilidade de ciclovias, usando Dimensões, Características e Indicadores de sustentabilidade. O modelo foi aplicado em um estudo de caso de duas ciclovias na Capital brasileira. O processo de escolha dos indicadores de sustentabilidade foi realizado pelo método de Delphi com 8 especialistas sêniores da área de transportes, e os originalmente 650 indicadores convergiram para 28 indicadores consolidados. A hierarquia das Dimensões, Características e dos Indicadores foi estabelecida pelo método de Função Multiatributo Aditiva (Multiattribute Utility Theory). Nove outros especialistas definiram níveis de importância, atribuindo pesos às Dimensões, Características e Indicadores. Foram atribuídos 40 pesos para todos os três níveis hierárquicos e o valor final do peso em cada nível foi representado pela média aritmética dos pesos dos 9 especialistas. Os pesos do nível hierárquico dos Indicadores foram ponderados, multiplicados pelos pesos de suas respectivas Características e Dimensões, resultando em uma equação de Índice de Sustentabilidade (SI) como uma combinação linear dos pesos com os indicadores.

Foi realizado um estudo de caso aplicando o modelo em duas ciclovias do Distrito Federal, Brasil. Entrevistas foram realizadas com 148 usuários na ciclovia 1, e 293 usuários na ciclovia 2, e os usuários atribuíram notas (Scores) entre 0 e 1 aos indicadores propostos. Aplicou-se então as notas (scores) dos indicadores dos entrevistados na Equação proposta, obtendo um valor do Índice de Sustentabilidade $(S I)$ para cada ciclovia. A ciclovia 2 apresentou maior sustentabilidade com SI de 0,78725 em comparação ao SI de 0,50965 para ciclovia 1. Em simulação estabelecendo pesos iguais para os Indicadores, o resultado do SI não varia muito, com 0,59821 para a ciclovia 1, e 0,77679 para a ciclovia 2. Em outra simulação atribuindo pesos iguais às Dimensões, a ciclovia 2 continua sendo mais sustentável, com o $S I$ de 0,81756 em comparação ao SI de 0,51158 para a ciclovia 1 .

Ficou demonstrada a importância de indicadores de sustentabilidade para avaliação de ciclovias. O trabalho demonstrou que há diferenças significativas entre ciclovias considerando as dimensões da sustentabilidade. 
A utilização de indicadores para ciclovias pode ser importante ferramenta para nortear o desenvolvimento de políticas públicas que envolvam o transporte urbano por meio de bicicletas. Os indicadores podem ser utilizados, por exemplo, para simulação de diferentes cenários de expansão de ciclovias, sendo possível sua utilização em um processo de tomada de decisões. Os indicadores apresentados neste trabalho podem ser aproveitados para avaliação de outras ciclovias em qualquer ambiente urbano. 


\section{Q Bibliografía}

》 Afgan, N. H., Carvalho, M. G., \& Hovanov, N. V.(2000). Energy system assessment with sustainability indicators. Energy Policy, 28(9), 603-612.

" Álvarez, M. R., \& Torrado-Fonseca, M. (2016). El método Delphi. REIRE. Revista d'Innovació i Recerca En Educació, 9(1), 87-102.

» Batabyal, A. A., \& Nijkamp, P. (2013). Ought a green citizen to bicycle or take public transport to work? Ecological Economics, 86, 93-96.

»Bellen, H. M. van. (2002). Indicadores de sustentabilidade: uma análise comparativa. Florianópolis, SC Retrieved from https://repositorio.ufsc.br/handl e/123456789/84033?show=full.

» Costa, M. da S. (2008, October 8). Um índice de mobilidade urbana sustentável. Biblioteca Digital de Teses e Dissertações da Universidade de São Paulo, São Carlos Retrieved from http://www.teses.usp.br/teses/disponiveis/18/18144/ tde-01112008-200521\%.

»Costa, P. B., Neto, G. C. M., \& Bertolde, A. I. (2017). Urban Mobility Indexes: A Brief Review of the Literature. Transportation Research Procedia, 25, 3645-3655.

"Dalkmann, H., \& Brannigan, C. (2007). Transport and climate change. Sustainable transport: A sourcebook for policy-makers in developing cities, Module 5e. GTZ. Disponível em www.sutp.org

»Elkington, J. (1994). Towards the Sustainable Corporation: Win-Win-Win Business Strategies for Sustainable Development. California Management Review, 36(2), 90-100.

» Faber, N., Jorna, R., \& Van Engelen, J. (2005). The sustainability of 'sustainability' - a study into the conceptual foundations of the notion of 'sustainability'. Journal of Environmental Assessment Policy and Management, o7(01), 1-33.

» Fernandez, F. N. (2014). Planejamento regional e o desafio da sustentabilidade. Política e Planejamento Regional , 1(1), 81-102.

»International Energy Agency. (2017). Key World Energy Statistics 2017. Paris Retrieved from https://www.iea.org/publications/freepublications/publication/ key-world-energy-statistics-2017.html.

» Jain, D., \& Tiwari, G. (2017). Sustainable mobility indicators for Indian cities: Selection methodology and application. Ecological Indicators, 79, 310-322.

»Litman, T. (1999) Reinventing transportation; exploring the paradigm shift needed to reconcile sustainability and transportation objectives, Transportation Research Record 1670, Transportation Research Board, www.trb.org, pp.8-12, disponível em www.vtpi.org

» Litman, T. (2008). Sustainable Transportation Indicators. Transportation, 65(November), 1-20.

» Massen, I., Svidén, O., \& Wegener, M. (1992). From growth to equity and sustainability: Paradigm shift in transport planning? Futures, 24(6), 539-558. doi: 10.1016/0016-3287(92)90116-W

" Miranda, D. M. (2012). Mapas das ciclovias do DF I Livros e bicicletas Retrieved from https://biciclotheka.wordpress.com/2012/o6/o6/mapas-das-ciclovias-do-df/. 
» Mitropoulos, L. K., \& Prevedouros, P. D. (2016). Incorporating sustainability assessment in transportation planning: an urban transportation vehicle-based approach. Transportation Planning and Technology, 39(5), 439-463.

» Parris, T. M., \& Kates, R. W. (2003). Characterizing and measuring sustainable development. Annual Review of Environment and Resources, 28(1), 559-586.

»Pearce, D. W., \& Atkinson, G. D. (1993). Capital theory and the measurement of sustainable development: an indicator of "weak" sustainability. Ecological Economics, 8(2), 103-108.

"Pezzey, J. (1992). Sustainable development concepts: an economic analysis (1st ed.). Washington: The World Bank Retrieved from http://documents.worldbank.org/ curated/pt/237241468766168949/pdf/multi-page.pdf.

»Pontes, T. F. (2010, July 29). Avaliação da mobilidade urbana na area metropolitana de Brasília. Universidade de Brasília Retrieved from http://repositorio.unb.br/ handle/10482/7789? mode=simple.

»Renne, J. L. (2008). Evaluating Transit-Oriented Development Using Sustainability Framework: Lessons from Perth's Network City. In Transportation Research Board 87th Annual Meeting (p. 42). Washington: Transportation Research Board.

"Repetto, R., \& Magrath, W. B. (1988). Natural resources accounting (1st ed.). Washington: World Resources Institute Retrieved from https://www.osti.gov/ biblio/6453840.

»Silva, A. N. R. da, Costa, M. da S., \& Ramos, R. A. R. (2010). Development and application of I_SUM - An index of Sustainable Urban Mobility. In Transportation Research Board Annual Meeting (p. 18). Washington.

"Turner, R. K. (1993). Sustainable environmental economics and management: principles and practice. Belhaven Press Retrieved from https://books.google.com. $\mathrm{br} /$ books/about/Sustainable_environmental_economics_and.html?id=2L5AAAAIAAJ\&redir_esc $=\mathrm{y}$.

»Velasco, C., Ramalho, G., Massuella, L., \& Reis, T. (2018). Malha cicloviária das capitais cresce $133 \%$ em 4 anos e já passa de 3 mil quilômetros | Economia | G1 Retrieved from https://g1.globo.com/economia/noticia/2018/08/28/ malha-cicloviaria-das-capitais-cresce-133-em-4-anos-e-ja-passa-de-3-milquilometros.ghtml.

"World Commission on Environment and Development. (1987). Our Common Future (1st ed.). London: Oxford.

»Yai, T., \& Suzuki, M. (2011). Current bicycle transport policies in the usa and direction of bicycle planning system in Japan. Journal of Japan Society of Civil Engineers, Ser. D3 (Infrastructure Planning and Management), 67(5), 67_I_15567_I_167.

\section{Renata Almeida Motta / renata_a_motta@hotmail.com}

Possui doutorado em Transportes pela Universidade de Brasília - UNB (Julho/2016), Mestrado em Engenharia de Transportes pela COPPE - Universidade Federal do Rio de Janeiro (Janeiro/2009) e graduação em Engenharia Ambiental pela Pontifícia Universidade Católica do Rio de Janeiro (2006). Atualmente trabalha no IBRAM - Instituto do Meio Ambiente e dos Recursos Hídricos do Distrito Federal. 


\section{Clarissa Melo Lima / limaclarissa@yahoo.com.br}

Graduada em Engenharia Química pela Universidade Federal do Ceará (2009), mestrado pelo departamento de Engenharia Florestal - Universidade de Brasília (2013), e doutorado em Ciências Florestais, também pela Universidade de Brasília (2017). É professora Colaboradora da Universidade de Brasília, da Faculdade de Economia, Administração, Contabilidade e Gestão Pública/FACE

\section{Augusto César de Mendonça Brasil / ambrasil@unb.br}

Possui graduação em Engenharia Mecânica pela Universidade Federal do Pará (1988), mestrado em Engenharia Ambiental pela Universidade Federal do Espírito Santo (1992), doutorado em Engenharia Mecânica pelo Instituto Superior Técnico da Universidade Técnica de Lisboa (2000) e Pós Doutorado pelo Instituto Superior Técnico na área de Consumo Energético e Emissão de Poluentes de Veículos de Transportes. Atualmente é professor associado da Universidade de Brasília.

\section{Paulo Cesar Marques da Silva / pcmsilva@unb.br}

Possui graduação em Engenharia Mecânica pela Universidade Federal da Bahia (1983), mestrado em Engenharia de Transportes pela Universidade Federal do Rio de Janeiro (1992) e doutorado em Transport Studies pela University of London (University College London) (2001). É professor adjunto da UnB - Universidade de Brasília. 